Canadian

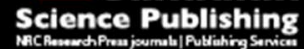

Canadian Journal of Chemistry Revue canadienne de chimie

\title{
Catalytic wet peroxide oxidation of phenol over ZnFe204 nano spinel
}

\begin{tabular}{|r|l|}
\hline Journal: & Canadian Journal of Chemistry \\
\hline Manuscript ID & cjc-2016-0220.R1 \\
\hline Manuscript Type: & Article \\
\hline Date Submitted by the Author: & 27-Aug-2016 \\
\hline Complete List of Authors: & $\begin{array}{l}\text { Hosseini, Seyed Ali ; Urmia university, Applied Chemistry } \\
\text { Farhadi, Khalil; Urmia University, Chemistry } \\
\text { Siakamari, Somaye; Urmia University } \\
\text { Azizi, Behruz; Urmia University }\end{array}$ \\
\hline Keyword: & Nano spinel, ZnFe2O4, wet peroxide oxidation, phenol, response surface \\
\hline & \multicolumn{2}{|l}{} \\
\hline
\end{tabular}




\title{
Catalytic wet peroxide oxidation of phenol over $\mathrm{ZnFe}_{2} \mathrm{O}_{4}$ nano spinel
}

\author{
S.A. Hosseini ${ }^{*}$, Kh. Farhadi ${ }^{\text {b }}$, S. Siahkamari ${ }^{\text {b }}$ B. Azizi ${ }^{\text {b }}$ \\ ${ }^{a}$ Department of Applied Chemistry, Faculty of Chemistry, Urmia University, Urmia, Iran \\ ${ }^{b}$ Department of Analytical Chemistry, Faculty of Chemistry, Urmia University, Urmia, Iran
}

\begin{abstract}
The catalytic wet peroxide oxidation (CWPO) of phenol was investigated over $\mathrm{ZnFe}_{2} \mathrm{O}_{4}$ nano spinel under different conditions, designed by the experimental design. $\mathrm{ZnFe}_{2} \mathrm{O}_{4}$ nano oxide was synthesized by the sol-gel combustion method and characterized by X-ray diffraction (XRD), Fourier transform infrared spectroscopy (FTIR) and scanning electron microscope (SEM) techniques. The mean particle size was determined around 80-90 nm. The experiments were designed by Box-Behnken type of response surface methodology (RSM) through considering four process variables: $\mathrm{C}_{\mathrm{H} 2 \mathrm{O} 2}(\mathrm{M}), \mathrm{ZnFe}_{2} \mathrm{O}_{4}$ amount $(\mathrm{g})$, temperature $\left({ }^{\circ} \mathrm{C}\right)$ and reaction time (min). The optimum condition for the degradation of the phenol was predicted by the response surface methodology. The optimal conditions for phenol degradation were at $0.144 \mathrm{M}, 0.156 \mathrm{~g}, 70{ }^{\circ} \mathrm{C}$ and $300 \mathrm{~min}$ of peroxide concentration, catalyst amount, temperature and reaction time, respectively. The predicted response under these conditions was $99 \%$, whereas the experimental test of predicted condition led to $97 \%$ degradation of phenol. Pareto analysis predicted that the order of relative importance of model terms is as follows:

Reaction temperature $(29 \%)>$ catalyst amount- reaction temperature $(19 \%)>$ reaction temperature- reaction time $(14 \%)>$ reaction time $(10.9 \%)>$ catalyst amount $(9.8 \%)$. The study revealed that zinc ferrite nano spinel could be promising for removal of pollutants by catalytic wet peroxide oxidation process.
\end{abstract}

Keywords: Nano spinel, $\mathrm{ZnFe}_{2} \mathrm{O}_{4}$, wet peroxide oxidation, phenol, response surface.

\footnotetext{
* Corresponding Author:

Email: s_ali_hosseini@yahoo.com
}

Tel.: +984432752026

Fax: +984432753172 


\section{INTRODUCTION}

Large amounts of hazardous organic products are annually released from industry to the environment. Effective cleaning of industrial wastewaters has become an increasingly concerning problem in the last decades. Modern legislation in many countries imposes environmental regulations and health quality standards are steadily becoming more restrictive [1].

Phenol and phenol-like compounds occupy a prominent position on the US EPA priority pollutants list due to the high toxicity of microorganisms, high chemical oxygen demand and poor biodegradability [2]. The presence of phenol even in trace amounts has been proven fatal to living beings [3]. Phenols frequently appear in wastewater from refineries, manufacture of petrochemical, pharmaceutical, coal processing, coking operations, and many other industries. There are several methods for removing organic waste from industries on the basis of biological, chemical and physical [4].

Therefore, considerable research efforts are focused on the development of efficient technologies to remove this type of pollutants. In the last decade, great research efforts have been addressed to advanced oxidation processes (AOPs), which usually operate at or near ambient temperature and pressure based on the action of hydroxyl radicals. Among them, the so-called catalytic wet peroxide oxidation (CWPO) appears as a promising solution in a short term, most particularly in the case of heterogeneous Fenton oxidation [1]. Active, economical and stable catalysts would play a critical role in the degradation of organic pollutants in CWPO. The catalytic wet peroxide oxidation (CWPO) process relies on the oxidation of suspended or diluted organic matter under mild operating conditions ( $\mathrm{T}=298-383 \mathrm{~K}$ ) using hydrogen peroxide as oxidant [5]. In the last 10 years, the attention has been focused on a different kind of supported transition metal ion (iron or copper) catalysts.

The spinel ferrites $\left(\mathrm{MFe}_{2} \mathrm{O}_{4}\right)$ are the most widely used in many applications including magnetic recording, ferrofluids, catalysis, gas desulfurization and magnetic resonance imaging [6-7]. These ferrites have the structural formula of, where $M$ is a divalent metal ion from the $3 \mathrm{~d}$ transition elements such as $\mathrm{Mn}, \mathrm{Cu}, \mathrm{Ni}, \mathrm{Co}, \mathrm{Zn}$ or combinations of these [6]. Among the spinel ferrites, zinc ferrite has long been the subject of study because of its unique properties such as chemical and thermal stability and the particle size dependent magnetic properties.

Spinel zinc ferrite $\mathrm{ZnFe}_{2} \mathrm{O}_{4}$ has attracted more attentions due to its interesting magnetic property and application in the catalysis. The application of magnetic particle technology to resolve environmental problems is one of several new and innovative methods that have received 
considerable attention in recent years. Compared with conventional separation, the advantages of magnetic separation come from its speed, accuracy, and simplicity [8].

The stability and activity of catalysts are also strongly dependent on the reaction conditions, including reaction temperature, $\mathrm{pH}$ in solution, reaction time, oxidant concentration and composition and concentration of pollutants.

One of the statistical techniques for design, modeling and optimization is response surface methodology (RSM), where the responses of interest are influenced by several process variables. RSM comprises the following three major components: (i) experimental design to determine the values of process factors based on which experiments are conducted and data are collected; (ii) empirical modeling to approximate the relationship (i.e. the response surface) between responses and factors; (iii) optimization to find the best response value based on the empirical model $[9,10]$. RSM is particularly applicable to problems where the understanding of the process mechanism is limited and/or is difficult to be represented by a first-principles mathematical model. Depending on specific objectives in practice, these RSM techniques differ in the experimental design procedure, the choice of empirical models, and the mathematical formulation of the optimization problem [11]. The objective of this work was to develop the magnetic $\mathrm{ZnFe}_{2} \mathrm{O}_{4}$ nano spinel in CWPO of phenol. Besides, in order to study the process and effect of effective variables on the removal of phenol with minimum experiments, Box-Behnken as taken for the design of experiments. The process is modeled and optimized in order to find a relationship between process variables and phenol removal per cent as well as the relative importance of independent factors on the response. The catalyst was characterized by XRD, FTIR, and SEM.

\section{EXPERIMENTAL}

\section{Preparation and characterization of $\mathrm{ZnFe}_{2} \mathrm{O}_{4}$}

The $\mathrm{ZnFe}_{2} \mathrm{O}_{4}$ catalyst was prepared using the sol-gel auto combustion process [12-14]. The analytical grade $\mathrm{Fe}\left(\mathrm{NO}_{3}\right)_{3} .9 \mathrm{H}_{2} \mathrm{O}, \mathrm{Zn}\left(\mathrm{NO}_{3}\right)_{2} \cdot 6 \mathrm{H}_{2} \mathrm{O}$ and citric acid monohydrate $\left(\mathrm{C}_{6} \mathrm{H}_{8} \mathrm{O}_{7} \cdot \mathrm{H}_{2} \mathrm{O}\right)$ were used as raw materials and purchased from Merck company (Germany). The stoichiometric amounts of nitrates were first dissolved into distilled water to form a mixed solution. Then the mixed solution was poured into a beaker and heated at $60{ }^{\circ} \mathrm{C}$ under constant stirring for $30 \mathrm{~min}$, citric acid was added and in the next step, solutions were evaporated at $90{ }^{\circ} \mathrm{C}$ by continuous stirring to form a viscous gel. Continues heating at $200{ }^{\circ} \mathrm{C}$ transformed viscous gel into a dried gel. The dried gel burnt in a self- combustion way to form a powder. Using a mortar and pestle, the resulting powder was milled to a fine powder and then subjected to heat treatment at $300^{\circ} \mathrm{C}$ for $2 \mathrm{~h}$ in a muffle furnace. Finally, the product was calcined in a furnace at $600^{\circ} \mathrm{C}$ for $7 \mathrm{~h}$ to obtain brown powder $\mathrm{ZnFe}_{2} \mathrm{O}_{4}$. 


\section{Phenol oxidation}

The catalytic oxidation process of phenol was carried out in a $250 \mathrm{~mL}$ three-neck glass flask fitted with a reflux condenser, a magnetic stirrer, and an oil bath. The catalyst was used without previous treatment. In a typical experiment, the mass of fresh catalyst was put into $100 \mathrm{ml}$ of $1 \mathrm{~g} \mathrm{~L}^{-1}$ of phenol aqueous solution $\mathrm{pH} 3.5$ (is adjusted with $\mathrm{HCl} 1$ mol. $\mathrm{L}^{-1}$ ) under continuous stirring at 500 $\mathrm{rpm}$. When the reaction temperature was reached, a given volume of $35 \% \mathrm{wt}$ hydrogen peroxide was added into the system and the reaction started. Liquid samples were taken at different time intervals and immediately analyzed. The phenol and products were detected and measured by HPLC. Hydrogen peroxide was detected by an iodometric titration method.

\section{Characterization of Catalysts}

The structure and crystal phase of the catalyst was investigated by a SIEMENS D500 diffractometer and $\mathrm{Cu} \mathrm{K}_{\alpha}$ radiation $\left(\lambda=1.54^{\circ} \mathrm{A}\right)$.

The FTIR spectra of the sample were recorded in transmittance at room temperature using a Bruker spectrometer (model TENSOR 27). The small amount of $\mathrm{ZnFe}_{2} \mathrm{O}_{4}$ powder was pressed into selfsupporting wafers of $10-15 \mathrm{mg} / \mathrm{cm}^{2}$ surface density and placed into a glass cell sealed by $\mathrm{KBr}$ windows.

The morphology of the mixed oxides was determined via scanning electron microscopy (SEM) by an EQ-C1-1 instrument precoating the samples with gold.

\section{Experimental design and modeling procedure}

In this study, a three-level Box-Behnken experimental design was used to evaluate the effects of selected independent variables on the responses (phenol removal \%). This design is suitable for exploration of quadratic response surfaces and for the construction of second order polynomial models, thus helping to optimize the process by using a small number of experimental runs. Four independent factors were considered as an effective factor on the phenol conversion in CWPO process: the peroxide concentration $(\mathrm{M})$, Catalyst amount $(\mathrm{g})$, reaction temperature $(\mathrm{C})$, and reaction time (min). The experimental ranges and levels of the independent test variables are presented in table 1 .

For the four-factorial Box-Behnken experimental design, a total of 27 experiments, shown in table 2 , are needed. In the optimization process, Box-Behnken results were used for calculating, where $Y$ is the selected response (dependent variable), $X_{1}$ to $X_{i}$ are the independent variables being optimized. 
Accordingly, the best combination of $\mathrm{x}_{1}$ (peroxide concentration), $\mathrm{x}_{2}$ (catalyst amount), $\mathrm{x}_{3}$ (reaction temperature), and $\mathrm{x}_{4}$ (reaction time) for maximizing phenol catalytic wet peroxide oxidation was obtained by using the above second-order polynomial equation 1 .

$$
Y=b_{0}+\sum_{i=1}^{n} b_{i} X_{i}+\sum_{i=1}^{n} b_{i i} X_{i}^{2}+\sum_{i=1}^{n-1} \sum_{j=i+1}^{n} b_{i j} X_{i} X_{j}
$$

Where $Y$ is the predicted response, $\mathrm{b}_{0}$ the constant coefficient, $\mathrm{b}_{\mathrm{i}}$ the linear coefficients, $\mathrm{b}_{\mathrm{ij}}$ the interaction coefficients, $b_{i i}$ the quadratic coefficients and $X_{i}$ and $X_{j}$ are the coded levels of the factors studied. The coefficients of determination, $R^{2}$ and $R_{\text {adj }}^{2}$ expressed the quality of fit of the resultant polynomial model, and statistical significance was checked by the F-test in the program. The desired goals in optimization were selected as the maximum response at amounts of independent variables.

\section{RESULTS AND DISCUSSIONS}

\section{Characterization of $\mathrm{ZnFe}_{2} \mathrm{O}_{4}$}

Fig.1. shows XRD pattern for the synthesized $\mathrm{ZnFe}_{2} \mathrm{O}_{4}$. The XRD pattern presented some peaks centered at $20,30^{\circ}, 35^{\circ}, 43^{\circ}, 54^{\circ}, 57^{\circ}$, and $62^{\circ}$ are indexed to (111),(220), (311), (400), (422), (511), and (440) crystal planes of cubic spinel $\mathrm{ZnFe}_{2} \mathrm{O}_{4}$. The mean crystallite sizes of oxides were estimated from the full width at half-maximum of the most intense and non-overlapped diffraction $\left(\sim 2 \theta=35^{\circ}\right)$, using Debye Scherrer equation (2):

$$
\mathrm{D}=\mathrm{K} \lambda /(\beta \cos \theta)
$$

Where $\mathrm{K}$ is a constant equals to 0.89 . Lambda $(\lambda)$ is the wavelength of the $\mathrm{X}$-ray and $\beta$ is the effective line width of the X-ray reflection. The mean crystallite size was estimated $40 \mathrm{~nm}$ using Debye formula.

\section{Fig.1. XRD spectra of $\mathrm{ZnFe}_{2} \mathrm{O}_{4}$}

Fig. 2 shows the FT-IR spectra of $\mathrm{ZnFe}_{2} \mathrm{O}_{4}$ in the range $500-4000 \mathrm{~cm}^{-1}$. The absorption sharp peaks of $\mathrm{ZnFe}_{2} \mathrm{O}_{4}$ appeared at $500-700 \mathrm{~cm}^{-1}$. The appearance of two bands in this region is the characteristic bands of the spinel-type oxides which correspond to the stretching vibration of metaloxygen bond. The band around $554 \mathrm{~cm}^{-1}$ is assigned to the vibration of zinc $(\mathrm{Zn})$ in the tetrahedral environment of oxygen atom ( $\mathrm{Zn}-\mathrm{O})$ and the band at $643 \mathrm{~cm}^{-1}$ corresponds to the vibration of $\mathrm{Fe}$ in the octahedral $(\mathrm{Oh})$ site of spinel. The appearance of these bands confirmed the formation of spinel structures. The difference in the position of the bands in the IR spectra of samples is due to the mutual interaction of metal ions $(\mathrm{Zn}, \mathrm{Fe})$ occurring in tetrahedral and octahedral sub-lattices 
respectively. The broad band in the region around $3400 \mathrm{~cm}^{-1}$ is attributed to the presence of coordinated water and bands around 1560 are ascribed to the presence of trace organic compounds [15].

\section{Fig. 2. IR spectra of $\mathrm{ZnFe}_{2} \mathrm{O}_{4}$}

In wet peroxide oxidation processes, hydrogen peroxide does not form any harmful by-products, and it is a non-toxic and ecological reactant. Moreover, although hydrogen peroxide is a relatively costly reactant, the peroxide oxidation compares very favorably to processes that use gaseous oxygen.

Oxidation of phenol furnishes more hydroxylated aromatic compounds that can be oxidized to quinones while further oxidation gives a complex mixture of organic compounds as reported schematically in Fig.3 [16].

Fig.3. Simplified scheme for phenol oxidation.

The morphology and particle size of catalyst were investigated by SEM (Fig.4). SEM image of the catalyst reveals that the mean particle size of the sample is in nano scale $(<100 \mathrm{~nm})$. In addition, the particles are in the spherical form with mean diameter $80-90 \mathrm{~nm}$. Considering the results of XRD and SEM analyses, it is resulted that each nanoparticle contains 2-3 crystallites.

\section{Fig.4: SEM image of $\mathrm{ZnFe}_{2} \mathrm{O}_{4}$}

\section{Results of RSM modeling}

The generated model contains quadratic terms explaining the non-linear nature of the responses. This design also resolves the two-factor interaction effects of individual terms and allows a midlevel setting (0) for the combination of factors [17]. The design consists of replicated center points and a set of points lying at the midpoints of each edge of the multidimensional cube that defines the region of interest. The model is of the following form:

\section{Modeling and Optimization of phenol CWPO}

In the present study Box-Behnken was used for the modeling and optimization of catalytic wet peroxide oxidation of phenol. A Box-Behnken experimental design, with a total number of 27 experiments was used for response surface modeling. The following second-order polynomial response equation was used to correlate the dependent and independent variables:

$$
\begin{aligned}
& Y=b_{0}+b_{1} x_{1}+b_{2} x_{2}+b_{3} x_{3}+b_{4} x_{4}+b_{12} x_{1} x_{2}+b_{13} x_{1} x_{3}+b_{14} x_{1} x_{4}+b_{23} x_{2} x_{3}+b_{24} x_{2} x_{4}+b_{34} x_{3} x_{4}+ \\
& b_{11} x_{21}+b_{22} x_{22}+b_{33} x_{23}+b_{44} x_{3} x_{4}
\end{aligned}
$$

Where $\mathrm{Y}$ is the response variable of phenol removal. The $b_{i}$ is regression coefficients for linear effects; $b_{i i}$ the regression coefficients for squared effects; $b_{i k}$ the regression coefficients for 
interaction effects and $\mathrm{x}_{\mathrm{i}}$ are coded experimental levels of the variables.

The experimental and predicted values for wet peroxide oxidation phenol are presented in table 2 .

Based on these results, an empirical relationship between the response and independent variables was attained and expressed by the following second-order polynomial equation:

$$
\mathrm{Y}=65.39+2.58 \mathrm{x}_{1}-6.25 \mathrm{x}_{2}+10.75 \mathrm{x}_{3}+6.58 \mathrm{x}_{4}+2.27 \mathrm{x}_{2}^{2}+2.77 \mathrm{x}_{3}^{2}+4.5 \mathrm{x}_{1} \mathrm{x}_{3}+4.0 \mathrm{x}_{1} \mathrm{x}_{4}-8.25 \mathrm{x}_{2} \mathrm{x}_{3}-
$$

$4.25 \mathrm{x}_{2} \mathrm{x}_{4}+7.5 \mathrm{x}_{3} \mathrm{x}_{4}$

The model predicts that among singular variables, the amount of catalysts with a negative coefficient $\left(\mathrm{X}_{2}\right)$ has a negative effect on the response (degradation of phenol), whereas $\mathrm{X}_{1}, \mathrm{X}_{3}$, and $\mathrm{X}_{4}$ have a positive effect on the response. Among binary terms, the interactions of $\mathrm{X}_{1} \mathrm{X}_{3}, \mathrm{X}_{1} \mathrm{X}_{4}$, and $\mathrm{X}_{3} \mathrm{X}_{4}$ have a positive effect on the response while $\mathrm{X}_{2} \mathrm{X}_{3}$ term has a negative impact on the response.

Table 3 shows the results of the quadratic response surface model fitting in the form of analysis of variance (ANOVA). ANOVA is required to test the significance and the adequacy of the model.

First of all, the significance of the model was investigated by the determination coefficient $\left(\mathrm{R}^{2}\right)$, which is a correlation criterion between the experimental and predicted values of the fitted data.

A graph of the experimental responses (phenol removal) plotted against the predicted responses by the model is shown in Fig .5. The determination coefficient between the predicted and observed values for the conversion was $95.54 \%$, confirming that experimental results are in good agreement with predicted results. This implies that $95.54 \%$ of the variations in phenol removal efficiency is explained by the independent variables and this also means that the model does not explain only $4.46 \%$ of the variation.

\section{Fig.5 Correlation between experimental and predicted responses.}

In addition, the adequacy of the models was evaluated by the residuals which are the difference between experimental and the predicted response value. The Normal probability plot in Fig.6 (a) shows the predicted response against the residual values, given by a normal distribution. A graph of the residual versus the predicted response shows random behaviour without a tendency towards residuals for experimental values (Fig.6 (b)). Fig.6(c) shows the plot of residuals versus order of data shows randomly scattering and consequently the residual plots approve the adequacy of the model. Furthermore, the Fisher's F-test was used to verify the statistical significance of the model. It is concluded from the results of F-test that the established model is statistically significant (i.e. ratio of mean square regression to mean square residual) with F-value of 29.18.

\section{Fig.6. Residual plots for CWPO of phenol}

On the other hand, the significance of the regression coefficient of the model terms was investigated by $\mathrm{P}$-value and t-value. P-value and $\mathrm{t}$-value of each term of the model are presented in 
table 4. The larger the magnitude of the t-value and smaller the P-value, the more significant is the corresponding coefficient [18].

The coefficients of the linear effect of time, peroxide concentration, catalyst amount and temperature with $\mathrm{p}$-value $<0.05$ were significant.

In the case of quadratic effects of $\left(\mathrm{X}_{\mathrm{i}}^{2}\right)$, just $\mathrm{X}_{3}^{2}$ (Temperature -Temperature) were significant at the confidence level of $95 \% . \mathrm{X}_{2}{ }^{2}$ was significant at the confidence level of $90.9 \% . \mathrm{X}_{1}{ }^{2}$ and $\mathrm{X}_{4}{ }^{2}$ were removed from the model because of the high value of p-value. In the case of binary terms, the interactions of $X_{1} X_{3}, X_{1} X_{4}, X_{2} X_{3}, X_{2} X_{4}$ and $X_{3} X_{4}$ were significant at a confidence level of $95 \%$ ( $p$ value $\leq 0.05$ ) and the other interactions were removed from the model because of the high value of p-value.

The importance of each term in the model was determined by Pareto analysis. It gives more significant information to interpret the results. Pareto analysis calculates the percentage effect of each term on the response, which is calculated by the following formula:

$$
P_{i}=\left(\frac{b_{i}^{2}}{\sum b_{i}^{2}}\right) \times 100(i \neq 0)
$$

Fig.7 shows the Pareto analysis. The results suggest that the reaction temperature with a relative importance of $29 \%$ and interaction of catalyst amount-reaction temperature with $17 \%$ of relative importance are the most important terms on the removal of the phenol. According to the Pareto analysis, the order of the relative importance of model terms is as follows: $X_{3}(29 \%)>X_{2} X_{3}(19 \%)$ $>\mathrm{X}_{3} \mathrm{X}_{4}(14 \%)>\mathrm{X}_{4}(10.9 \%)>\mathrm{X}_{2}(9.8 \%)$. So, it is concluded that there is the following order between the relative importance of independent factors: $X_{3}>X_{4}>X_{2}>X_{1}$.

\section{Fig.7. Results of Pareto analysis}

In addition, in order to study the binary interactions of factors, the three-dimensional (3D) response surface plots and two-dimensional (2D) contour plots were used. 3D plots are graphical representations of the established regression equation (Eq. 4) to achieve a better understanding of the interactions between factors and to determine the optimum level of each factor for maximum degradation of phenol. The 2D contour plot is the projection of 3D surface plot on a two dimensional page.

Fig. 8 illustrates 3D surface plot and 2D contour plots for the combined interaction of peroxide concentration and reaction time on the catalytic wet peroxide oxidation of phenol. It was resulted from the figure that maximum degradation is at a high level of temperature and mid and a high level of peroxide concentration. 
Fig .8. The response surface plot and contour plot of the degradation efficiency of phenol as a function of peroxide concentration and temperature.

Fig.9 shows the 2D contour plot and 3D surface plot for interaction of peroxide concentration and reaction time. It was found from this figure that increasing the value of both peroxide concentration and reaction time leads to increase the degradation of phenol. At peroxide concentration above 0.2 and a reaction time above $250 \mathrm{~min}$, high phenol degradation is resulted.

Fig .9. The response surface plot and contour plot of the degradation efficiency of phenol as a function of peroxide concentration and reaction time

In the case of the binary interactions of reaction time and temperature also the high degradation of phenol is observed at high value of the factors and $\mathrm{x}_{1} \mathrm{x}_{4}$ exhibited a positive effect on the response, as shown in Fig. 10.

Fig.10. The response surface plot and contour plot of the degradation efficiency of phenol as a function of temperature and reaction time

Furthermore, the optimum condition for the degradation of the phenol was predicted by the response surface methodology. The optimum condition was at $0.144 \mathrm{M}, 0.156 \mathrm{~g}, 70{ }^{\circ} \mathrm{C}$ and 300 min of peroxide concentration, catalyst amount, temperature and reaction time, respectively. The predicted response under these conditions was $99 \%$, whereas the experimental test of predicted condition led to $97 \%$ degradation of phenol.

\section{CONCLUSIONS}

$\mathrm{ZnFe}_{2} \mathrm{O}_{4}$ nano spinel was successfully synthesized by sol-gel combustion method and characterized by XRD, FTIR, and SEM. Its performance in the catalytic wet peroxide oxidation of phenol was investigated. Response surface methodology allowed studying of the peroxide oxidation process by a minimum number of experiments and saving cost and time. In addition, it provided to develop a model for the process in order to predict the degradation of phenol at different values of peroxide concentration, catalyst amount, temperature and reaction time. Analysis of variance of the model showed a high value for the determination coefficient $\left(\mathrm{R}^{2}=0.9554\right)$, thus ensuring a satisfactory adjustment of the second-order regression model with the experimental data. The Pareto analysis suggested that order of relative importance of the factors to be as follows: reaction temperature $>$ catalyst amount-temperature $>$ temperature-reaction time $>$ reaction time $>$ catalyst amount. Under optimum conditions, $99 \%$ degradation of phenol was predicted by the RSM and $97 \%$ was resulted 
in practice. The study indicated that nano spinel oxides could be promising catalysts for CWPO process for waste water pollutants. The testing of another structure of metal mixed oxides for the removal of phenol is under study.

\section{NOMENCLATURE}

CWPO: Catalytic wet peroxide oxidation

RSM: Response Surface Methodology

XRD: X-ray Diffraction

FTIR: Fourier transform infrared spectroscopy

SEM: scanning electron microscopy

AOPs: Advanced oxidation processes

\section{ACKNOWLEDGEMENTS}

Especially thank Iranian Nanotechnology Initiative Council for financial supports.

\section{REFERENCES}

(1) Zazo, J.A.; Bedia, J.; Fierro, C.M.; Pliego, G.; Casas, J.A.; Rodriguez, J.J. Catal. Today 2005, 187, 115-121.

(2) Melero, J.A.; Calleja, G.; Martínez, F.; Molina, R.; Pariente, M.I. Chem. Eng. J. 2007, 131, 245-256.

(3) Kurian, M.; Sugunan, S. Chem. Eng. J. 2006, 115, 139-146.

(4) Inchaurrondo, N.S.; Massa, P.; Fenoglio, R.; Font, J.; Haure P. Chem. Eng. J. 2012, 198199, 426-434.

(5) Quintanilla, A.; García-Rodríguez, S.; Dominguez, C.M.; Blasco, S.; Casas, J.A.; Rodriguez, J.J. Appl. Catal. B 2012, 111-112, 81-89.

(6) Raeisi Shahraki, R.; Ebrahimi, M. JNS 2013, 2, 413-416. 
(7) Ikenaga, N.; Ohgaito, Y.; Matsushima, H.; Suzuki, T. Fuel 2004, 83, 661-669.

(8) Ladole, C.A. Int. J. Chem. Sci. 2012, 10(3), 1230-1234.

(9) Khataee, A. R.; Zarei, M.; Moradkhannejhad, L. Desalination, 2010, 258, 112-119.

(10) Salari, D.; Niaei, A.; Aghazadeh, F.; Hosseini, S.A.; Seyednajafi, F. J. Environ. Sci. Health Pt. A, 2012, 47, 351-357.

(11) Tang, Q.; Lau, Y.; Hu, S.; Yan, W.; Yang, Y.; Chen, T. Chem. Eng. J. 2010, 156, 423-431.

(12) Salker, A.V.; Gurav, S. M.; Mater. Sci. 2000, 35, 4713-4719.

(13) Hosseini, S.A.; Salari, D.; Niaei, A.; Deganello, F.; Pantaleo, G.; Hojatti, P. J. Environ. Sci. Health Part A 2011, 46, 291-297

(14) Zavyalova, U.; Nigrovski, B.; Pollok, K.; Langenhorst, F.; Müller, B.; Scholz, P.; Ondruschka, B. Appl. Catal. B. 2008, 83, 221-228.

(15) Hosseini, S.A.; Alvarez-Galvan, M.C.; Fierro, J.L.G.; Niaei, A.; Salari, D. Ceram Int.2013, 39, 9253-9261.

(16) Liotta, L.F.; Gruttadauria, M.; DiCarlo, G.; Librando, G. P. J. Hazard Mater, 2009, 162, 588-606.

(17) Domínguez, C.M.; Ocón, P.; Quintanilla, A.; Casas, J.A.; Rodriguez, J.J.; Appl. Catal. B 2014, 144, 599-606.

(18) Hosseini, S. A.; Niaei, A.; Salari, D.; Nabavi, S.R. J. Taiwan Inst. Chem. Eng., 2014, 45, 85-91. 
Table 1. Experimental ranges and levels of the independent test variables

\begin{tabular}{|l|l|l|l|l|}
\hline \multirow{2}{*}{ Variables } & \multirow{2}{*}{ Symbol } & \multicolumn{3}{|c|}{ Ranges of levels } \\
\cline { 3 - 5 } & & -1 & 0 & +1 \\
\hline Peroxide concentration (M) & $\mathrm{X}_{1}$ & 0.1 & 0.3 & 0.5 \\
\hline Catalyst amount $(\mathrm{g})$ & $\mathrm{X}_{2}$ & 0.1 & 0.3 & 0.5 \\
\hline Reaction temperature $\left({ }^{\circ} \mathrm{C}\right)$ & $\mathrm{X}_{3}$ & 25 & 47.5 & 70 \\
\hline Reaction time (min) & $\mathrm{X}_{4}$ & 100 & 200 & 300 \\
\hline
\end{tabular}


Table 2. The 4-factor Box-benhken design matrix and the value of responses

\begin{tabular}{|c|c|c|c|c|c|}
\hline $\begin{array}{l}\text { Peroxide } \\
\text { concentration }\end{array}$ & $\begin{array}{l}\text { Catalyst } \\
\text { loading }(\mathrm{g})\end{array}$ & $\begin{array}{l}\text { Reaction } \\
\text { temperature } \\
\left({ }^{\circ} \mathrm{C}\right)\end{array}$ & Time (min) & $\begin{array}{l}\text { Experimental } \\
\text { Response (\%) }\end{array}$ & $\begin{array}{l}\text { Predicted } \\
\text { Response (\%) }\end{array}$ \\
\hline 0.3 & 0.3 & 70.0 & 300 & 93.6759 & 92.9931 \\
\hline 0.3 & 0.1 & 47.5 & 300 & 85.4259 & 84.7431 \\
\hline 0.5 & 0.3 & 47.5 & 100 & 56.8426 & 57.3889 \\
\hline 0.3 & 0.3 & 47.5 & 200 & 66.4815 & 65.3889 \\
\hline 0.3 & 0.5 & 47.5 & 100 & 59.7593 & 59.0764 \\
\hline 0.1 & 0.3 & 25.0 & 200 & 58.3704 & 59.3264 \\
\hline 0.3 & 0.1 & 47.5 & 100 & 63.7593 & 63.0764 \\
\hline 0.1 & 0.3 & 70.0 & 200 & 70.8704 & 71.8264 \\
\hline 0.3 & 0.1 & 70.0 & 200 & 95.9537 & 95.6806 \\
\hline 0.5 & 0.3 & 25.0 & 200 & 54.5370 & 55.4931 \\
\hline 0.5 & 0.1 & 47.5 & 200 & 76.7870 & 76.4931 \\
\hline 0.3 & 0.5 & 25.0 & 200 & 61.9537 & 61.6806 \\
\hline 0.1 & 0.3 & 47.5 & 100 & 59.6759 & 60.2222 \\
\hline 0.1 & 0.3 & 47.5 & 300 & 64.8426 & 65.3889 \\
\hline 0.3 & 0.5 & 47.5 & 300 & 64.4259 & 63.7431 \\
\hline 0.3 & 0.3 & 47.5 & 200 & 66.4815 & 65.3889 \\
\hline 0.5 & 0.5 & 47.5 & 200 & 61.7870 & 63.9931 \\
\hline 0.1 & 0.5 & 47.5 & 200 & 59.1204 & 58.8264 \\
\hline 0.3 & 0.3 & 25.0 & 100 & 59.0093 & 58.3264 \\
\hline 0.5 & 0.3 & 47.5 & 300 & 78.0093 & 78.5556 \\
\hline 0.3 & 0.3 & 47.5 & 200 & 66.4815 & 65.3889 \\
\hline 0.3 & 0.5 & 70.0 & 200 & 66.9537 & 66.6806 \\
\hline 0.3 & 0.3 & 25.0 & 300 & 57.1759 & 56.4931 \\
\hline 0.1 & 0.1 & 47.5 & 200 & 69.1204 & 71.3264 \\
\hline 0.5 & 0.3 & 70.0 & 200 & 85.0370 & 85.9931 \\
\hline 0.3 & 0.1 & 25.0 & 200 & 57.9537 & 57.6806 \\
\hline 0.3 & 0.3 & 70.0 & 100 & 65.5093 & 64.8264 \\
\hline
\end{tabular}


Table 3. Analysis of variance (ANOVA) for the quadratic response surface model

\begin{tabular}{ccccc}
\hline $\begin{array}{c}\text { Source of } \\
\text { variations }\end{array}$ & Sum of squares & $\begin{array}{c}\text { Degree of } \\
\text { freedom }\end{array}$ & $\begin{array}{c}\text { Adjusted mean } \\
\text { square }\end{array}$ & F-value \\
\hline Regression & 3238.95 & 11 & 294.45 & 29.18 \\
Residuals & 151.35 & 15 & 10.09 & \\
Total & 3390.30 & 26 & & \\
\hline $\mathrm{R}^{2}=95.54 \%, \mathrm{R}^{2}(\mathrm{pred})=85.53 \%, \mathrm{R}^{2}(\operatorname{adj})=92.26 \%$ &
\end{tabular}

Table 4. Estimated regression coefficient and corresponding $\mathrm{t}$ and $\mathrm{p}$ value

\begin{tabular}{cccc}
\hline Term & coefficient & T-value & p-value \\
\hline constant & 65.39 & 61.76 & 0.000 \\
$\mathrm{X}_{1}$ (peroxide concentration) & 2.583 & 2.84 & 0.013 \\
$\mathrm{X}_{2}$ (Catal amount) & -6.25 & -6.82 & 0.000 \\
$\mathrm{X}_{3}$ (temperature) & 10.75 & 11.72 & 0.000 \\
$\mathrm{X}_{4}$ (time/min) & 6.583 & 7.18 & 0.000 \\
$\mathrm{X}_{2} * \mathrm{X}_{2}$ & 2.27 & 1.81 & 0.091 \\
$\mathrm{X}_{3} * \mathrm{X}_{3}$ & 2.77 & 1.26 & 0.043 \\
$\mathrm{X}_{1} * \mathrm{X}_{3}$ & 4.5 & 2.83 & 0.013 \\
$\mathrm{X}_{1} * \mathrm{X}_{4}$ & 4.00 & 2.52 & 0.024 \\
$\mathrm{X}_{2} * \mathrm{X}_{3}$ & -8.25 & -5.19 & 0.000 \\
$\mathrm{X}_{2} * \mathrm{X}_{4}$ & -4.25 & -2.68 & 0.017 \\
$\mathrm{X}_{3} * \mathrm{X}_{4}$ & 7.5 & 4.72 & 0.000 \\
\hline
\end{tabular}


Figure Captions

Fig.1. XRD spectra of $\mathrm{ZnFe}_{2} \mathrm{O}_{4}$

Fig. 2. IR spectra of $\mathrm{ZnFe}_{2} \mathrm{O}_{4}$

Fig.3. Simplified scheme for phenol oxidation.

Fig.4: SEM image of $\mathrm{ZnFe}_{2} \mathrm{O}_{4}$

Fig.5 Correlation between experimental and predicted responses.

Fig.6. Residual plots for CWPO of phenol

Fig.7. Results of Pareto analysis

Fig .8. The response surface plot and contour plot of the degradation efficiency of phenol as a function of peroxide concentration and temperature.

Fig .9. The response surface plot and contour plot of the degradation efficiency of phenol as a function of peroxide concentration and reaction time

Fig.10. The response surface plot and contour plot of the degradation efficiency of phenol as a function of temperature and reaction time 


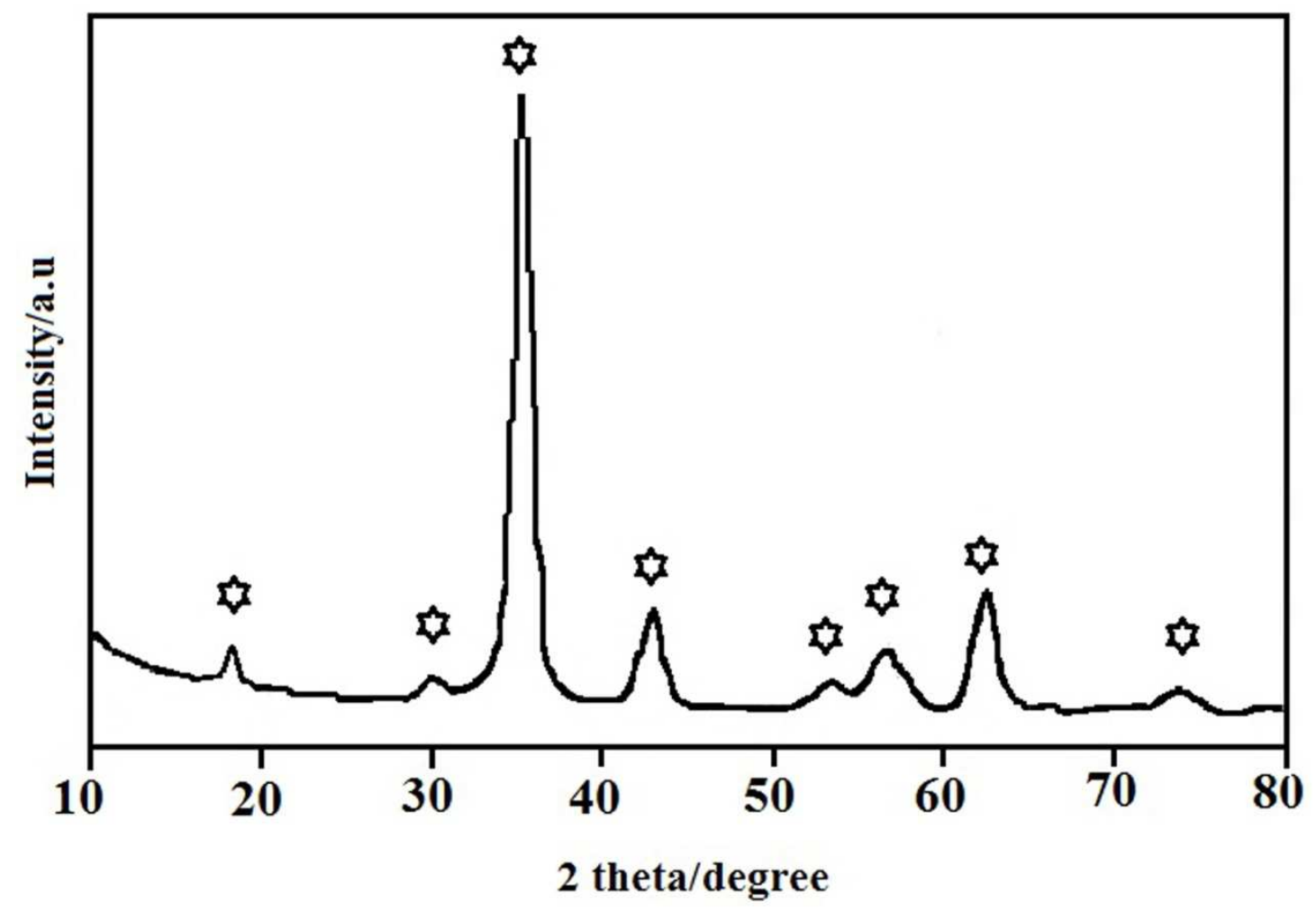

Fig.1

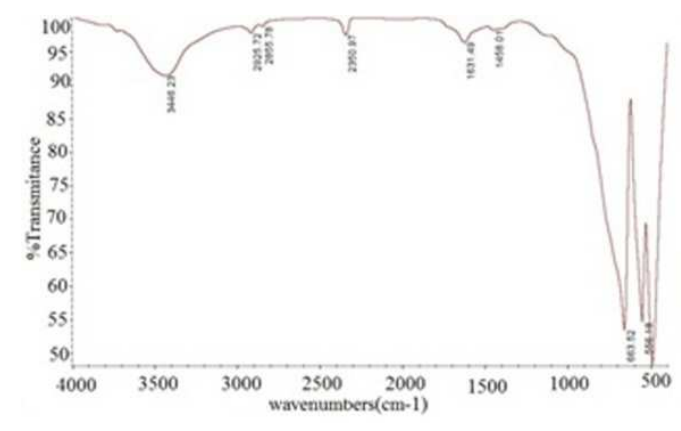

Fig. 2 


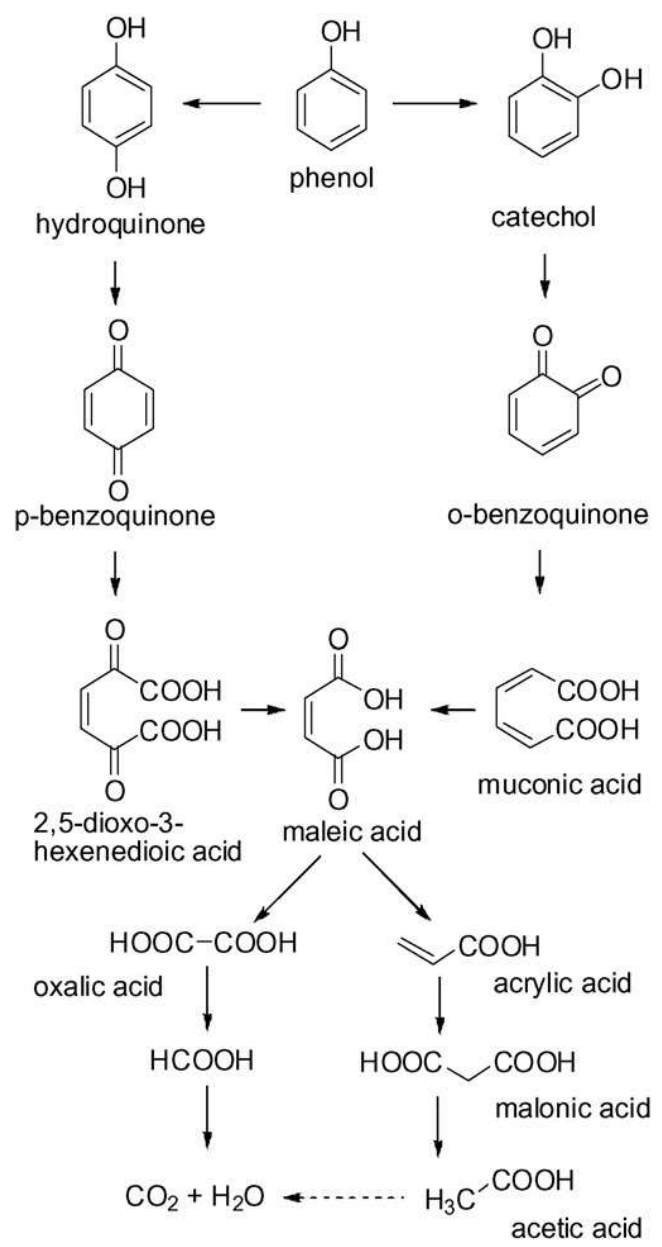

Fig.3 


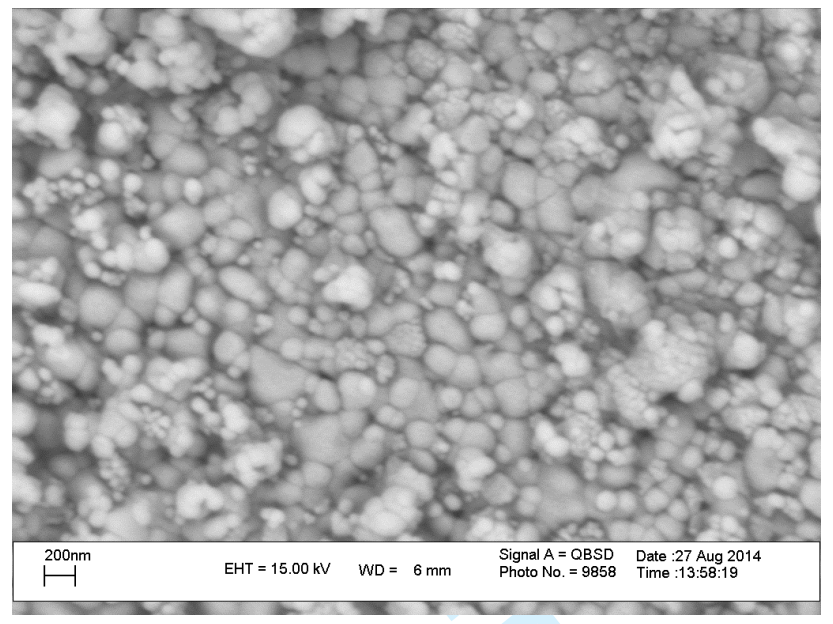

Fig.4 


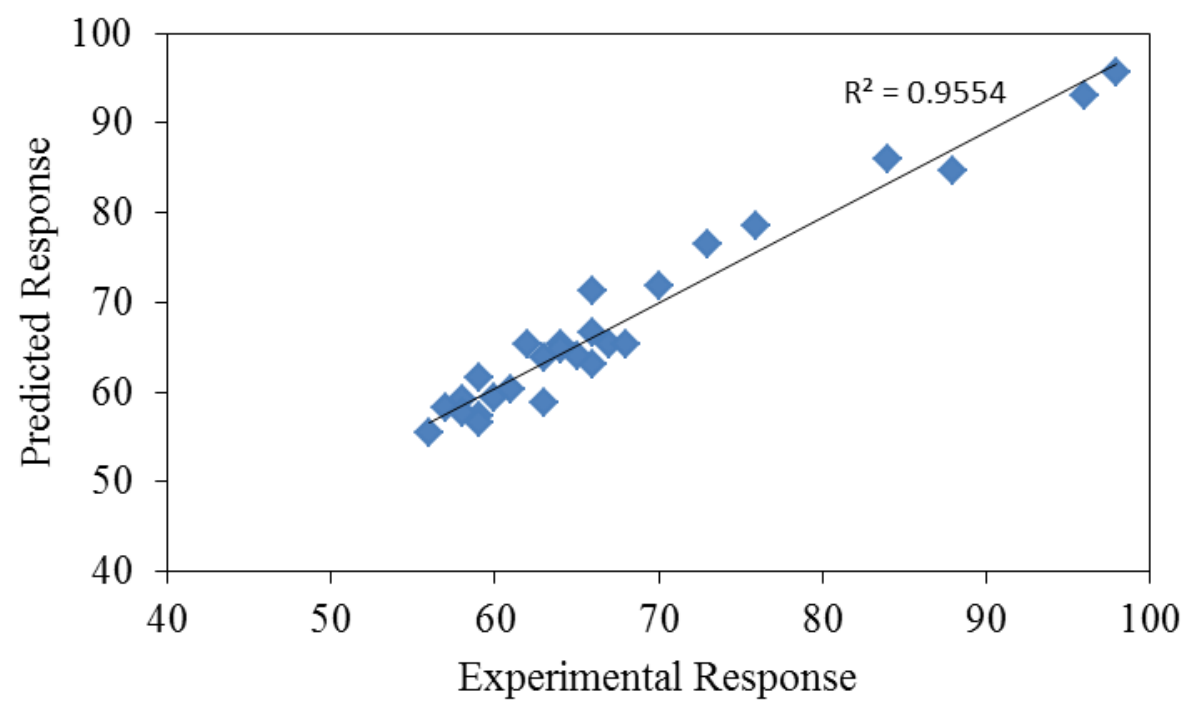

Fig.5 
(a)

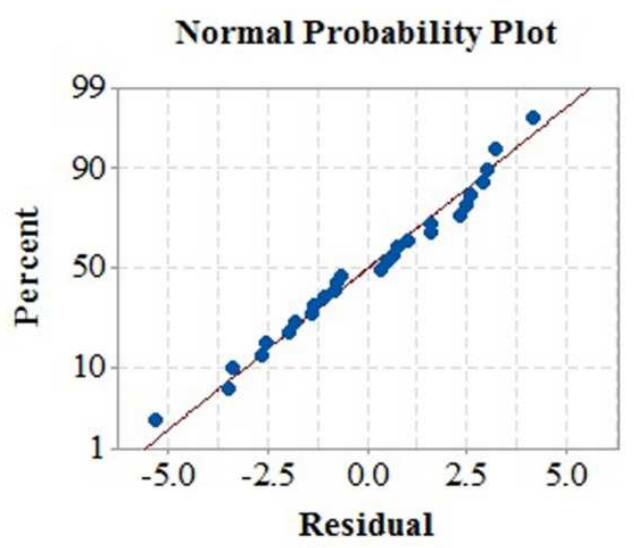

(b)

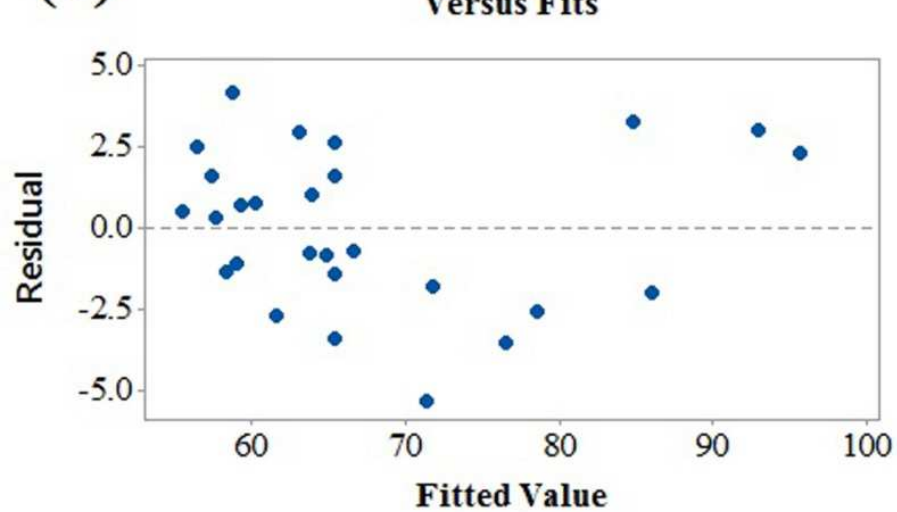

(c)

Versus Order

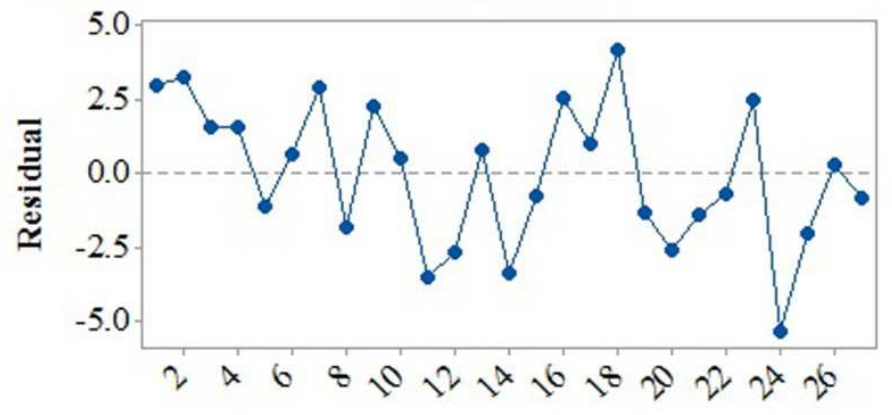

Observation Order

Fig.6 


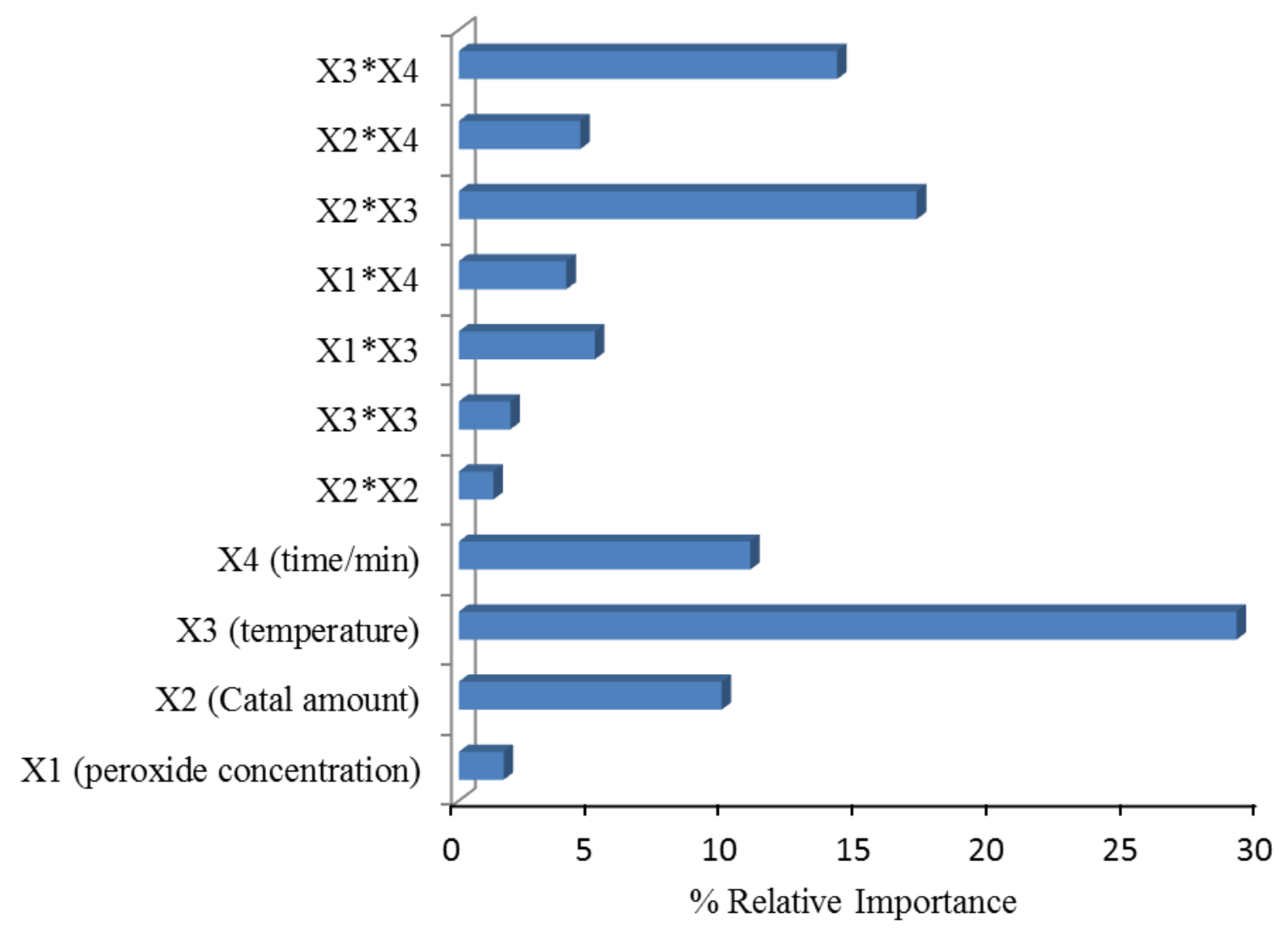

Fig.7 

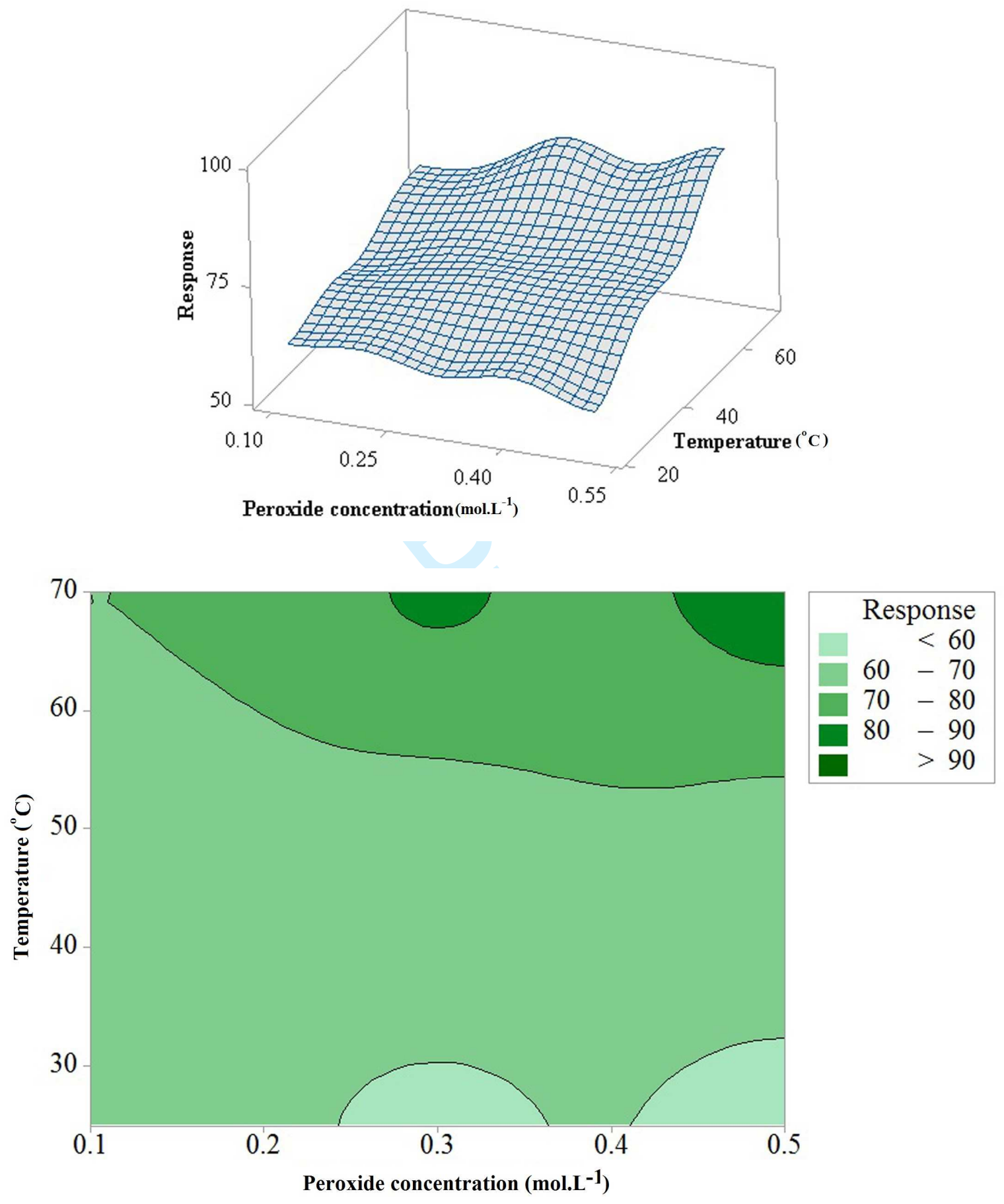

Fig. 8 

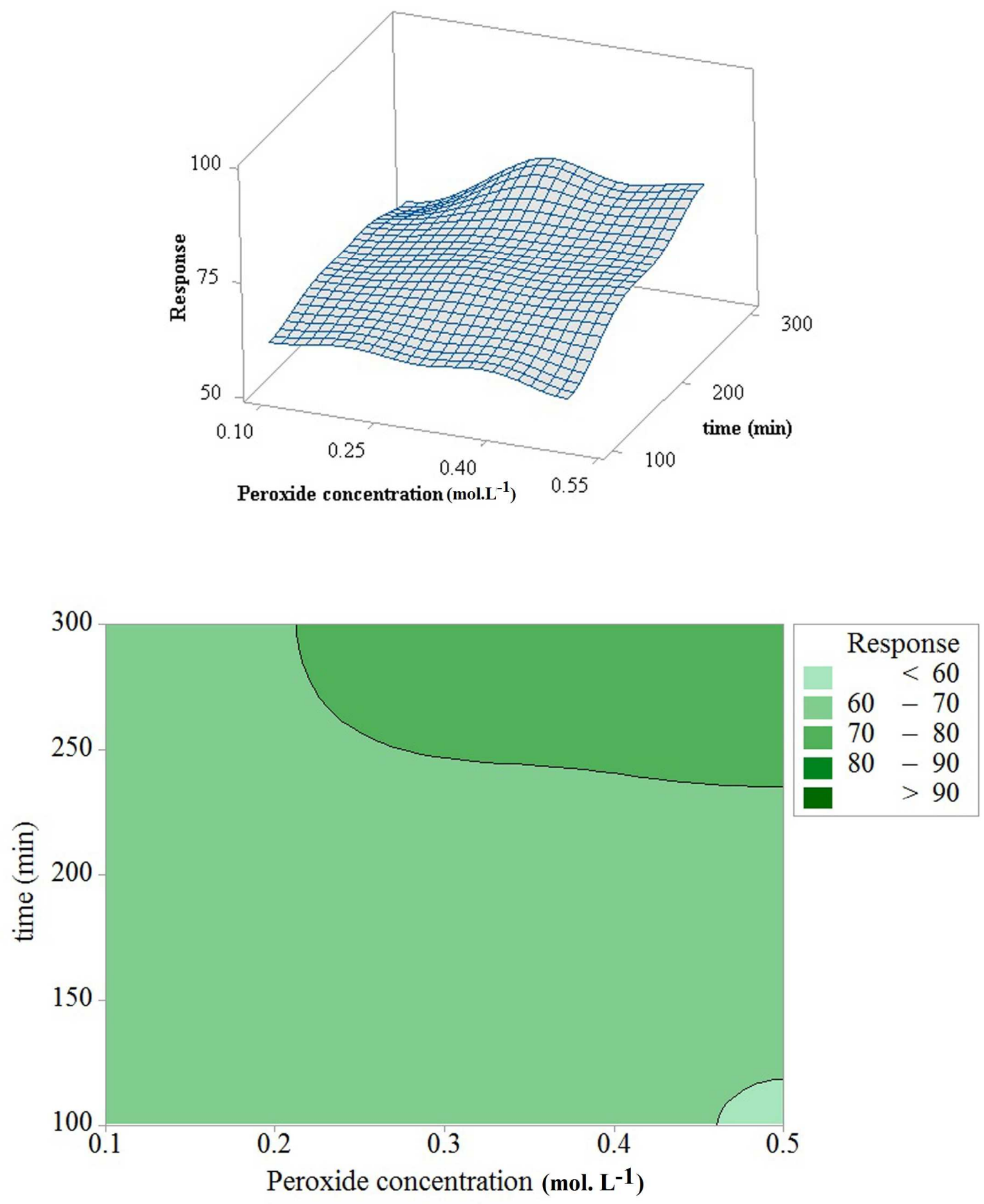

Fig.9 

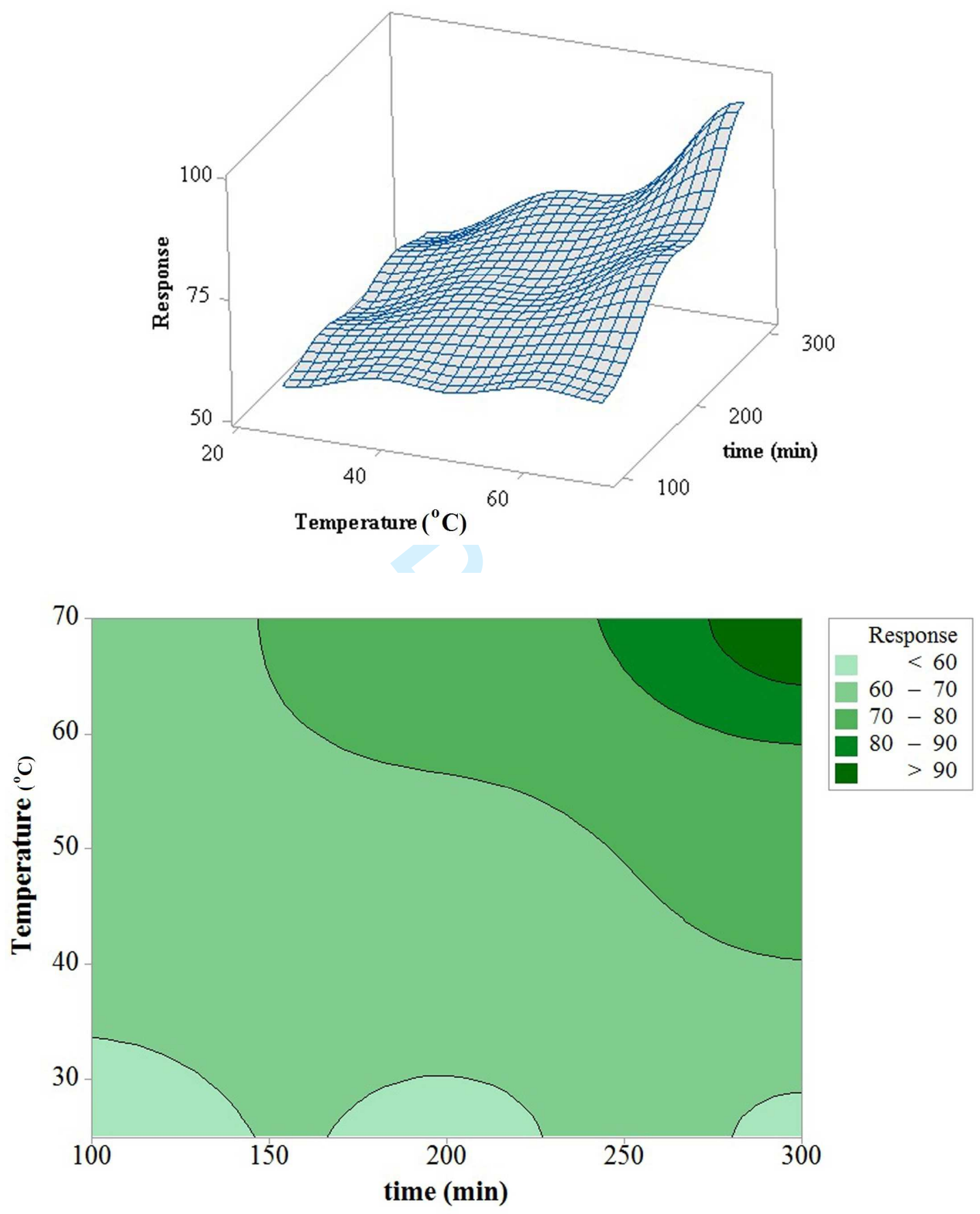

Fig. 10 